\title{
Analysis on the financing structure of Sichuan Changhong
}

\author{
Fandong Zhao*1, Yichao $\mathrm{Cai}^{1}$ and $\mathrm{Hao} \mathrm{Li}^{1}$ \\ ${ }^{1}$ Air force early warning Academy, Wuhan, Hubei province, 430019, China
}

\begin{abstract}
Reasonable financing structure is of great significance to the healthy development of enterprises. It can improve the operation and management of enterprises, enhance the financing ability of enterprises and promote the effective allocation of market resources. In this paper, the analysis of the capital structure of Sichuan Changhong found that the capital structure of Sichuan Changhong is not reasonable enough, in view of this problem to put forward some suggestions and improvement measures, not only can make Sichuan Changhong close to the optimal capital structure, improve its own quality and investment value, but also can enhance investors' confidence in Sichuan Changhong.
\end{abstract}

\section{Introduction}

Under the current market situation of the rapid development of market economy and the accelerating process of economic globalization, listed companies will retreat if they do not advance[1]. Financing structure is generally considered as capital structure, which refers to the composition and proportion of various long-term capital sources of an enterprise[2]. Financing structure is not only a micro-issue related to the development of companies, but also a macro-issue related to the development of national economy[3]. China's current economic system and financing system is difficult to guide the financing activities of Chinese enterprises, so it is necessary to conduct in-depth analysis of the financing structure of Chinese enterprises. Financing difficulty has become the bottleneck restricting the development of small and medium-sized enterprises, where the imbalance of financing structure is a very important reason[4]. In this paper, it is based on the analysis of the financing structure of Sichuan Changhong, finds the problems existing in the production and operation process, and puts forward measures and suggestions in time to improve the financing ability of Sichuan Changhong, so that it can maintain its profitability for a long time, which is of great significance to improve the management system and formulate the future development strategy.

\section{Sichuan Changhong financing structure analysis}

\subsection{Current status of Sichuan Changhong's financing scale}

Sichuan Changhong is a well-known national enterprise brand in China, it has transformed from a single military enterprise into a comprehensive multinational enterprise group with household appliances, video and audio appliances[5]. The financing scale of Sichuan Changhong from 2016 to 2020 is listed in the following table:

Table1. The scale of Sichuan Changhong's financing from 2016 to 2020 Unit: ten thousand yuan

\begin{tabular}{cccccc}
\hline & 2016 year & 2017 year & 2018 year & 2019 year & 2020 year \\
\hline short term loan & $1,389,690.49$ & $1,406,718.06$ & $1,574,212.20$ & $1,731,947.44$ & $1,684,359.10$ \\
long term loan & $69,000.88$ & $95,316.00$ & $10,192.00$ & $116,593.98$ & $179,154.90$ \\
$\quad$ long term & $20,580.76$ & $8,166.73$ & $1,269.78$ & $2,681.33$ & $13,449.63$ \\
accounts payable & $461,624.42$ & $461,624.42$ & $461,624.42$ & $461,624.42$ & $461,624.42$ \\
\hline paid-in capital & &
\end{tabular}

The corresponding histogram in table 1 is shown in the following figure: 


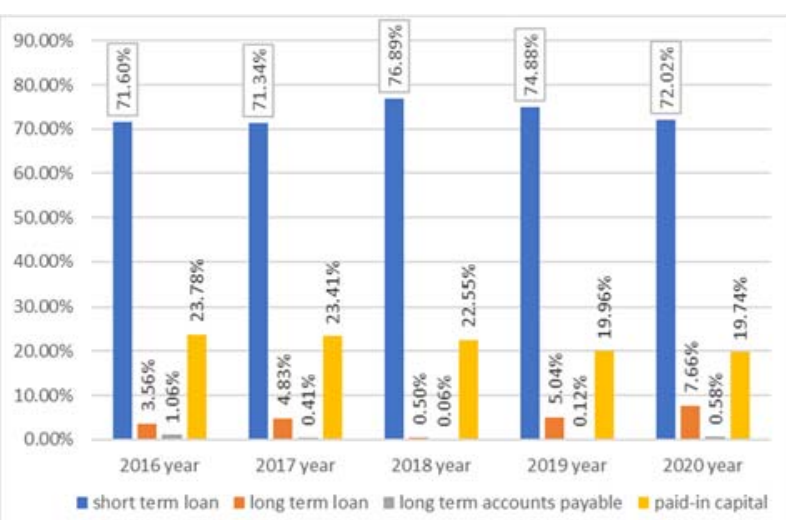

Figure 1. financing scale of Sichuan Changhong from 2016 to 2020

According to data analysis, Sichuan Changhong's short-term borrowing has been above $71 \%$, while the total financing from other channels is no more than $30 \%$. Therefore, it can be seen that the financing structure of Sichuan Changhong is not reasonable enough. The reasons are not only that the financing structure cannot be rationalized in a long period due to the imperfection of China's financial market at present, but also that there are many problems in Changhong itself, such as too conservative financing decisions and too limited channels. However, from the perspective of the development trend from 2016 to 2020, in addition to the paid-in capital remaining unchanged, Sichuan Changhong's short-term borrowings showed a slightly decreasing trend after 2018, and the proportion of long-term borrowings also increased. With the gradual development of China's financial market, it is found that the financing structure of Sichuan Changhong is gradually approaching the edge of rationalization, and the financing means are also rich, such as financial liabilities.

\subsection{Sichuan Changhong financing structure management}

2.2.1 Analysis of capital structure of Sichuan. Changhong. Generally speaking, the appropriate range of an enterprise's asset-liability ratio is $40 \%$ $60 \%$. The capital structure of Sichuan Changhong from 2016 to 2020 is listed in Table 2 below:

Table2. Capital structure of Sichuan Changhong from 2016 to 2020.

\begin{tabular}{ccccc}
\hline years & $\begin{array}{c}\text { Assets (ten } \\
\text { thousand yuan) }\end{array}$ & $\begin{array}{c}\text { Liabilities (ten } \\
\text { thousand yuan) }\end{array}$ & $\begin{array}{c}\text { Asset liability ratio } \\
(\%)\end{array}$ & $\begin{array}{c}\text { Industry average asset } \\
\text { liability ratio (\%) }\end{array}$ \\
\hline 2016 year & $5,986,297.40$ & $3,983,421.66$ & $66.54 \%$ & $53.68 \%$ \\
2017 year & $6,542,269.31$ & $4,456,586.10$ & $68.12 \%$ & $55.29 \%$ \\
2018 year & $7,150,493.89$ & $5,008,131.65$ & $70.04 \%$ & $58.30 \%$ \\
2019 year & $7,398,921.39$ & $5,285,364.13$ & $71.43 \%$ & $63.08 \%$ \\
2020 year & $7,811,401.36$ & $5,731,293.84$ & $73.37 \%$ & $62.42 \%$ \\
\hline
\end{tabular}

In order to analyze the data in table 2 conveniently and intuitively, draw its trend diagram, and the results are shown in Figure 2:

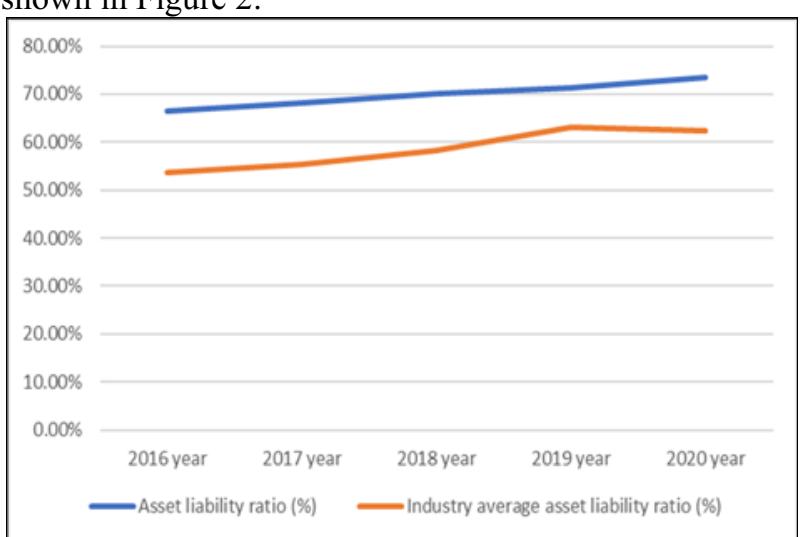

Figure 2. Capital structure of Sichuan Changhong from 2016 to 2020

From Figure 2, it can be seen that the asset-liability ratio of Sichuan Changhong has always been higher than the average level of the industry, about 10 percentage points higher. Sichuan Changhong's asset-liability ratio was the lowest in 2016 , at about $66.54 \%$, where an industry average of $53.68 \%$. From 2016 to 2020 , it can be seen that the asset-liability ratio of the whole industry has been increasing at the same time. In 2018, the debt ratio of Sichuan Changhong increased to $70.04 \%$, which was mainly caused by the merger evaluation of Changhong Huanyi enterprises, accelerated depreciation of fixed assets of Changhong Mealing and the increase of gold lease financing business in this year. In 2019, the assetliability ratio increased to $71.43 \%$, which was mainly caused by the increase of short-term financing and the increase of borrowings of subsidiaries in this year. In 2020, the debt ratio reached $73.37 \%$, mainly due to the increase of new non-current liabilities due within one year in the current period. The asset-liability ratio of Sichuan Changhong was above $66 \%$ from 2016 to 2020 . The assetliability ratio is higher than that of the same industry. From a positive point of view, it shows that the enterprise has made full use of financial leverage. However, from a negative point of view, the company's financial cost is higher, the risk is greater, and the solvency is weak[6]. It shows that the debt burden of Sichuan Changhong has been increasing in recent years, and the assets used to repay the debt are relatively tight, and the long-term solvency of the enterprise is weak.

However, the liabilities of Sichuan Changhong are basically current liabilities, with a proportion of more than $90 \%$. The specific data are listed in Table 3: 
Table3. Debt structure of Sichuan Changhong from 2016 to 2020.

\begin{tabular}{cccc}
\hline years & $\begin{array}{c}\text { Current liabilities (ten } \\
\text { thousand Yuan) }\end{array}$ & $\begin{array}{c}\text { Liabilities (ten } \\
\text { thousand Yuan) }\end{array}$ & $\begin{array}{c}\text { Current liabilities ratio } \\
(\%)\end{array}$ \\
\hline 2016 year & $3,769,726.50$ & $3,983,421.66$ & $94.64 \%$ \\
2017 year & $4,154,935.42$ & $4,456,586.10$ & $93.23 \%$ \\
2018 year & $4,784,922.23$ & $5,008,131.65$ & $95.54 \%$ \\
2019 year & $4,956,349.10$ & $5,285,364.13$ & $93.77 \%$ \\
2020 year & $5,413,712.65$ & $5,731,293.84$ & $94.46 \%$ \\
\hline
\end{tabular}

The ratio of current liabilities to total liabilities is generally around $50 \%$. Although the excessive current liabilities can reduce the financing cost to some extent, it also increases the short-term debt repayment burden of enterprises, thus increasing the financial risk and operational risk, which is extremely unfavorable to the sound operation of enterprises.

\subsubsection{Sichuan Changhong capital structure optimization analysis.}

Table4. Calculation table of financial leverage coefficient in 2016-2020 Unit :(ten thousand yuan)

\begin{tabular}{cccccc}
\hline & 2016 year & 2017 year & 2018 year & 2019 year & 2020 year \\
\hline Profit before interest & 170201.92 & 97548.93 & 224449.59 & 119216.23 \\
and taxes & $26,014.13$ & $2,342.66$ & 132689.03 & 52692.61 \\
Financial expenses & $144,187.79$ & $95,206.27$ & $91,760.56$ & $66,523.62$ \\
The total profit & $115,943.43$ & $66,135.34$ & $66,076.02$ & $66,523.62$ & $4,877.06$ \\
Profit after tax & 0.113 & 0.077 & 0.07 & 0.0131 & -0.028 \\
Earnings per share & & & & 0.028 \\
\hline
\end{tabular}

As shown in Table 4 above, although the indicators of Sichuan Changhong decreased slightly from 2016 to 2020, it can be seen from the financial leverage coefficient that the change rate of the increase and decrease of the profit before interest and tax is less than the change rate of the earnings per share of common stocks, that is, the fixed capital cost of each dollar of profit before interest and tax will be reduced accordingly. Thus to the common shareholders to bring certain financial leverage benefits. Among them, the profit before interest and tax in 2019 was reduced by 10,5233,600 yuan compared with that in 2018, the financial expense was reduced by $799,964,200$ yuan, and the financial leverage coefficient was 1.73 yuan. Compared with 2019, the annual profit before interest and tax in 2020 decreased by $867,101,500$ yuan, the financial expense decreased by $250,635,900$ yuan, and the financial leverage coefficient was 4.314 , indicating that the increase in performance brought the positive effect of financial leverage to the enterprise, and the risk was low, and the enterprise gained financial leverage benefits.

\section{Sichuan Changhong financing structure of the existing problems}

\subsection{The scale of short - and long-term financing is unbalanced}

According to the analysis of the debt structure table 3 of Sichuan Changhong, more than $90 \%$ of its liabilities are current liabilities, while the long-term liabilities are less than 10\%. Thus, Sichuan Changhong financing scale imbalance phenomenon. Reasonable long-term liabilities should be about 30\%-60\%. Although Sichuan Changhong has strong short-term debt paying ability and less pressure on long-term debt paying, the excessively conservative financing method will make the financing structure of the enterprise unreasonable and the enterprise value cannot be maximized.

\subsection{The financing structure is too homogeneous}

It can be found from the financial statements of Sichuan Changhong that in the long-term and short-term financing, the proportion of short-term financing is as high as $90 \%$, while the short-term bank loan is more than $40 \%$. Thus, it can be seen that the financing structure of Sichuan Changhong still takes bank loans as the main financing method. The structure is relatively single and the financing risks are too concentrated, which restricts the development of enterprises. Especially in the economic downturn, the credit crunch, to the enterprise borrowing, repayment and financing caused huge pressure.

\subsection{Lack of innovative financing for the structure}

For an enterprise, to raise funds quickly and efficiently is the key to a firm foothold and long-term development. It is understood that China's enterprise financing methods depend on a single, mostly to banks and other financial institutions. In fact, venture capital, private capital, venture financing, financial leasing and so on are good financing channels.

The rapid development of the Internet promotes the arrival of the era of big data. Many enterprises are facing the pressure of elimination and transformation. Obviously, Sichuan Changhong is no exception. The Internet brings challenges as well as new opportunities. The effective use of Internet financing can greatly reduce the financing cost of enterprises, improve the financing efficiency and broaden the financing channels, thus promoting the rationalization of the financing structure of enterprises and maximizing the value of enterprises to the greatest extent. 


\section{Improve financing suggestion \\ Sichuan structure} reasonable

\subsection{Balanced financing scale}

Through the analysis of the factors that affect the financing structure of enterprises, it can be found that a reasonable financing structure is of great significance to the sustainable, healthy and stable development of enterprises. From the perspective of financing failure, it is necessary for enterprises to calculate financing costs carefully. Under the same conditions, we should choose the financing structure with the lowest financing cost as far as possible to reduce the impact of financing cost on the financing structure. In addition, from the perspective of financing risk, enterprises must attach great importance to the control of financing risk and choose the financing method with less risk as far as possible. Only in the process of financing, reasonable choice of financing structure, to achieve the organic combination of long-term and short-term funds and debt funds, in order to effectively avoid and reduce the risk.

\subsection{Enrich financing channels and improve financing structure}

Expand financing channels appropriately. In recent years, equity financing and bond markets have developed to a certain extent, which makes the rationalization of the financing structure of listed companies play an important role. The government will improve development-related investment institutions, continue to develop the bond and stock markets, appropriately simplify the listing process of enterprises, improve the liquidity of the bond and stock markets, and establish and improve the securities credit rating system. According to the development of the market, the conditions for issuing bonds and stocks should be set up, the enterprise supervision system under the effective supervision of the government should be established, the issuance of corporate bonds should be gradually promoted, the proportion of bond financing of listed companies should be increased, the financing channels should be broadened, and the financing structure of listed companies should be rationalized. By issuing stocks and bonds, listed companies can avoid the risks brought by a single method, so as to ensure the healthy and stable operation of listed companies.

\section{5 conclusion}

Sichuan Changhong financing structure found in the analysis of the problems are: first of all, too resistant to external financing. In theory, endogenous financing has low cost, no restrictions on use and almost no risk. The cost of equity financing and debt financing is high and the risk is large, but Chinese enterprises prefer equity financing. Second, too much preference for short-term financing. Through analysis, it is found that the short-term financing rate of Sichuan Changhong is as high as $90 \%$, while the ratio of current liabilities to total liabilities is generally about 50\%. Although the excessive current liabilities can reduce the financing cost to some extent, it also increases the short-term debt repayment burden of enterprises, thus increasing the financial risk and operational risk, which is extremely unfavorable to the sound operation of enterprises. In combination with the actual situation of Sichuan changhong, aiming at the problems puts forward some Suggestions and improvement measures, hope to put forward Suggestions to improve Sichuan changhong and industry enterprise current capital structure has a guiding role, strive for an early form is most suitable for their own capital structure, make the company progresses day by day, to the audiovisual equipment industry in our country have made outstanding contributions.

\section{References:}

1. He, B. (2020) Financial performance analysis of Sichuan Changhong Group. J. Cooperative Economy and Science \& Technology., 21: 147-149.

2. Li, M., Dai, J. (2021) From the financing structure to see the financial risk of enterprises -- a case study of Chinese ships. J. China Economic and Trade Guide., 03: 133-135.

3. Shi, Q.U. (2011) Analysis of financing structure of listed companies in China. J. Market Modernization., 22:66.

4. Liu, Q.Q. (2021) Research on the financing structure problems and countermeasures of small and mediumsized enterprises. J. Small and medium-sized enterprises management and technology., 04: 99-100.

5. Li, S.Q. (2019) Analysis of the Impact of Financing Structure on Corporate Income -- Taking Sichuan Changhong as an Example. J. Modern Marketing (Information Edition), 08:44.

6. Yang, Y. J. (2013) Analysis on the capital structure of Sichuan Changhong Group. J. China Agricultural Accounting, 06:24-26. 